\title{
Impact of Religious Activities on Quality of Life and Cognitive Function Among Elderly
}

\author{
Syazwan Nazri Amir ${ }^{1} \cdot$ Norsham Juliana $^{1}$ (D) Sahar Azmani ${ }^{1}$.

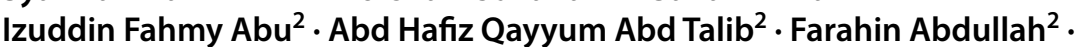 \\ Intan Zulaikha Salehuddin ${ }^{2}$. Nur Islami Mohd Fahmi Teng ${ }^{3} \cdot$ Nur Azma Amin ${ }^{2}$. \\ Nor Amira Syahira Mohd Azmi ${ }^{1}$ • Nur Adilah Shuhada Abd Aziz ${ }^{1}$
}

Accepted: 21 August 2021 / Published online: 18 September 2021

(C) The Author(s), under exclusive licence to Springer Science+Business Media, LLC, part of Springer Nature 2021

\begin{abstract}
Religiosity and spirituality have previously been found to have significant effects on mental and physical health. This study aimed to compare elderly people utilizing different types of religious activities in their daily routine and the effects upon their quality of life and cognitive function. A cross-sectional study was conducted among elderly people dwelling in suburban areas of Malaysia. The Malay version of Short Form (36) Health Survey (SF-36), Geriatric Depression Scale (GDS-15), Older Americans Resources and Services's Instrumental Activities of Daily Living (OARS's IADL), and the Montreal Cognitive Assessment (MoCA) questionnaires were used in this study. Independent t test was utilized to determine the difference in the quality of life and the cognitive function between groups of elderly people that were categorized based on their level of participation in different religious activities. The study involved 432 participants. The mean score for all domain of SF-36 was significantly higher among those who engaged in the religious activities as compared to those elderly who were either less engaged or did not practice religious activities. The mean score of GDS-15, OARS's IADL, and MoCA was also significantly higher among those who participated in religious activities. There was a significant impact on the quality of life and cognitive function among elderly people practicing religious activities. This study proved the importance of practicing religious activities among the elderly in achieving healthy aging.
\end{abstract}

Keywords Quality of life · Cognitive function · Elderly $\cdot$ SF-36 $\cdot$ MoCA $\cdot$ OARS's IADL · GDS-15

Norsham Juliana

njuliana@usim.edu.my

Extended author information available on the last page of the article 


\section{Introduction}

Biologically, human will experience aging caused by the accumulation effect of a wide variety of molecular and cellular damage over time. These damages will lead to further decrease in physical and mental capability, high risk of disease, and eventually causing death (World Health Organization, WHO, 2018). According to the Department of Statistic Malaysia (DOSM), the composition of population 65 years old and over increased from 6.5 to $6.7 \%$ and the life expectancy at birth for Malaysia population remained as high as 74.5 years (Department of Statistics Malaysia, DOSM, 2018).

Increased longevity and longer life expectancy have made quality of life (QoL) as an important issue to be addressed among this population (Hall et al., 2011). Quality of life epitomizes satisfaction with life including physical health, wealth, employment, safety, education, family, and security to freedom, religious beliefs, and the environment (Barcaccia et al., 2013). There are many factors that can affect individual's quality of life which include socioeconomic, demography, and health status. Moreover, as individual aged, the cognitive functioning also will be declined. They are susceptible to neurodegenerative disorder and age-associated cognitive impairment (Harada et al., 2013; Prince et al., 2016; Teeters et al., 2016). Cognitive impairment is concerning in view it is a clinically dominant comorbidity that influences the presentation and management of concomitant conditions (Perry et al., 2018). Hence, maintaining elderly's cognitive health is crucial to achieve healthy aging. Abnormalities can be in the form of the onset of dementing disorders which may impact on individual's daily life (Hosseini et al., 2019; Perry et al., 2018).

Despite the technology advancement available nowadays, we know very little of the impact of religion, spirituality, and/or belief may have on the health of the elderly. Some studies found that religiosity and spirituality can be a factor that can affect individual's quality of life (Mat Saad et al., 2010). Spirituality was found to be as one of the domains of elderly's quality of life whereby being religious and spiritual could help the elderly to accept disability or psychological distress, cope with changes, and be satisfied with their life (van Leeuwen et al., 2019). Religious engagement may contribute to a conservative part in health, avoiding health complications or assist in the adaptation or cure the health problems, and can be a factor in dealing with chronic conditions as well as the impairment they cause (Malone \& Dadswell, 2018). In other cases, religion can play a more consoling function and can be activated to cope with illness or stress, resulting for correlations between religion and health measures (Malone \& Dadswell, 2018). Besides that, previous study also found that religious activities are positively associated with the preservation of cognitive function (Wang et al., 2012).

Islam is a major religion in Malaysia, accounted for $61.3 \%$ of the Malaysian population (DOSM, 2011). One of the basic and mandatory acts in Islamic beliefs is the five times of obligatory prayers daily. Obligatory prayer is an act of worship that is specific and unique to Islam both in its form and spirit. Obligatory prayer is an act of obedience to the Supreme Creator Allah and is expressed in a particular 
and precise physical act embodying the spirit. All Muslims are ordained to perform obligatory prayers daily as a duty as well as the second pillar of the belief. Before performing obligatory prayer, Muslims need to perform ablution by washing their hands, face, and feet in a specific order. Ablution is an act of maintaining a high level of cleanliness and spiritual purity to ensure that the obligatory prayer can be performed with a clean body and clear intention of the worshiper to enter into a state of mind appropriate to communicate with Allah (Sayeed \& Prakash, 2013). After ablution has been made, an expression of intention to perform prayer called Niyyah needs to be done within one's heart appropriately for the prayer of the time. Through Niyyah, the worshiper is committed to complete the action as prescribed according to the prayer's rules in order one's prayer is accepted and rewarded by God (Sayeed \& Prakash, 2013).

The five times obligatory prayers are spread throughout the day as a mean of ensuring the frequent contact of the worshiper and Creator and receives peace and blessings as his reward as well as has been scientifically proven to allow the worshiper experiencing physical well-being (Sayeed \& Prakash, 2013). Obligatory prayer involves several physical movements in which a single Raka' a has three major movements. Firstly, in a standing position, the individual raises his hands to the level of his ears while pronounces 'Allahu Akbar' (Allah is the Greatest) after performing his Niyyah silently, and later, folds his hands above the navel. The individual will then recite Al-Fatihah, the opening surah of the Muslim holy book, namely the Al-Quran, followed by any other verses from the Al-Quran. The recitation of the Al-Quran verses is recited either silently or aloud, depending upon the time of prayer. The second movement is called ruku' (bowing down) whereby the individual bows with his hands rested on his knees and the back held straight $\left(90^{\circ}\right.$ position) for a few seconds enough to utter the supplication glorifying Allah for at least three times. Then, the individual rises up from the ruku' position to a standing position for a few seconds while praises Allah before the individual goes down to perform the third movement of obligatory prayer called 'sujud' (prostration). In this position, the individual's forehead, nose, palms of both hands, knees, and both toes are touching the ground. This position is the most cherished position in Islamic prayer whereby ruku' position acts as the individual is nearest to The Almighty. At this position, the individual again utters the supplication glorifying Allah for at least three times, and later, he rises to sit on his legs and repeats the prostration. Performing these three movements shows that the individual has completed one unit of prayer (raka'as). Typical Islamic prayer of a couple of raka'ah will be completed with tashahud position in which the individual sits on the legs and knees again and raises the right index finger and utters more supplications and salutation to Allah.

The effort to integrate indigenous knowledge from religious practices in Islam has caused increase in awareness on the effectiveness and the benefits of its application to the human health (Sayeed \& Prakash, 2013). However, most of studies only focused on biological and social factors; thus, data on the influence of religiousbased activities on quality of life and cognitive function among the elderly are still lacking. Therefore, this study aims to determine the impact of religious-related activities on the quality of life and cognitive function among elderly. 


\section{Materials and Methods}

\section{Design and Sample Size}

This cross-sectional study involved elderly respondents residing at suburban area of Malaysia. All Malaysian elderly aged 60 years and above who are literate in either English or Bahasa Malaysia were eligible to participate in this study. Elderly with underlying psychotic mental illness, diagnosed with terminal diseases including those who are currently under palliative care, and have congenital or genetic disorders were excluded in this study. An informed consent form containing all the necessary information about the study was provided to the respondents and was signed by and obtained from the respondents who agreed to participate in the study.

\section{Instrument}

This study involves assessing both the participants' quality of life and cognitive performance based on their religious activities. Religious activities that were practiced by the participants in this study were performing obligatory prayers, midnight prayer, recite Al-Quran daily, and fasting.

\section{Assessment of Quality of Life}

Three instruments were used in this study to assess the respondents' quality of life. This includes Malay version of Short Form 36 (SF-36), Geriatric Depression Scale15 (GDS-15), and Older Americans Resources and Services's Instrumental Activities of Daily Living (OARS's IADL). The Malay version of SF-36 questionnaire consists of 36 items assessing eight domains of quality of life: physical functioning (PF), role limitations due to physical problem (RP), bodily pain (BP), general health perception $(\mathrm{GH})$, social functioning $(\mathrm{SF})$, role limitations due to emotional problems (RE), vitality (VT), and mental health (MH). It was translated and validated by Sararaks et al. (2005). Each domain was scored ranging from 0 to 100 in which higher scores indicate better quality of life. Moreover, GDS-15 questionnaire was also used to measure the depression scale of the elderly as part of their quality of life assessment. It consists of 15 questions of which 10 questions indicated the presence of depression when answered positively; meanwhile, the other 5 questions, specifically question number $1,5,7,11$, and 13, indicated depression when answered negatively (Greenberg, 2019). GDS-15 scores ranged from 0 to 15 in which lower GDS-15 (less than 5) score indicates no depression, thus representing better quality of life (Greenberg, 2019). Besides that, this study also used OARS's IADL questionnaire to assess the functional aspect of the quality of life. The OARS's IADL subscale evaluates patients' independence in seven instrumental tasks. For a total score ranging from 0 to 14 points, the questionnaire used three levels of scoring $(0=$ fully dependent; $1=$ requiring some assistance; 2 =fully independent). Functional impairment was 
demonstrated by a score of less than ten points (Fillenbaum \& Smyer, 1981; Harith \& Tan, 2020).

\section{Assessment of Cognitive Function}

For cognitive function assessment, the Montreal Cognitive Assessment (MoCA) questionnaire was used. MoCA has been shown to be sensitive in identifying person with mild cognitive impairment (Dominguez et al., 2013). MoCA consists of different cognitive domains which were attention and concentration, executive functions, memory, language, visuoconstructional skills, conceptual thinking, calculations, and orientation. MoCA scores ranged from 0 to 30 points in which higher scores represent better cognitive functioning (specifically a score of 25 and above was considered normal) (Nasreddine et al., 2005).

\section{Data Analysis}

All statistical analyses were performed using Statistical Package of Social Science (SPSS) (version 23). Independent t test was used to compare the mean score of all of the instruments (SF-36, GDS-15, OARS's IADL, and MoCA) with different religious activities performed by the respondents. Pearson Chi-square test was used to determine the potential association of sociodemographic status (socioeconomy status, physical activity, and educational level) with GDS-15, OARS's IADL, and MoCA score, and the associations were further confirmed with logistic regression analysis. All statistical analyses were conducted at the significance level of 0.05.

\section{Results}

\section{General Characteristics of Respondents}

The study had successfully recruited 432 respondents with 244 (56.5\%) males and 188 (43.5\%) females. Majority of the participants were Malay, married, had formal education up to secondary school (Sijil Pelajaran Malaysia, SPM), and pensioner (Table 1).

In addition, this study found that majority of the respondents practiced five times of obligatory prayers accompany with sunnah prayer (76.4\%) and most of the respondents recite Al-Quran daily (69\%). However, this study also showed that most of the respondents did not practiced midnight prayer (67.6\%) and fasting $(70.1 \%)$ in their daily life (Table 2).

\section{Assessment of Respondents' Quality of Life and Cognitive Function}

The quality of life of the respondents was first measured and compared using SF-36 mean scores. For obligatory prayer activity, there was significant difference in the mean score of SF-36 among different obligatory prayer practices in all of SF-36 
Table 1 Sociodemographic characteristics of respondents $(\mathrm{N}=432)$

\begin{tabular}{|c|c|c|}
\hline Variables & Frequency $(\mathrm{N})$ & Percentage $(\%)$ \\
\hline \multicolumn{3}{|l|}{ Gender } \\
\hline Male & 244 & 56.5 \\
\hline Female & 188 & 43.5 \\
\hline \multicolumn{3}{|l|}{ Ethnicity } \\
\hline Malay & 366 & 84.7 \\
\hline Chinese & 48 & 11.1 \\
\hline Indian & 15 & 3.2 \\
\hline Other & 4 & 0.9 \\
\hline \multicolumn{3}{|l|}{ Marital status } \\
\hline Single & 25 & 5.8 \\
\hline Married & 303 & 70.1 \\
\hline Divorce & 12 & 2.8 \\
\hline Widower & 22 & 5.1 \\
\hline Widow & 69 & 16.0 \\
\hline \multicolumn{3}{|l|}{ Education } \\
\hline SPM & 351 & 81.3 \\
\hline STPM & 21 & 4.9 \\
\hline Diploma & 29 & 6.7 \\
\hline Degree & 22 & 5.1 \\
\hline Post-graduate studies & 9 & 2.1 \\
\hline \multicolumn{3}{|l|}{ Working status } \\
\hline Not working & 66 & 15.3 \\
\hline Self-working & 68 & 15.7 \\
\hline Work with employer & 11 & 2.5 \\
\hline Pensioner & 287 & 66.4 \\
\hline \multicolumn{3}{|l|}{ Disease } \\
\hline Cancer & 9 & 2.1 \\
\hline Arthritis & 67 & 15.5 \\
\hline Hypertension & 250 & 57.9 \\
\hline Diabetes & 157 & 36.3 \\
\hline No disease & 77 & 17.8 \\
\hline Other & 196 & 45.4 \\
\hline \multicolumn{3}{|l|}{ Exercise } \\
\hline Yes & 141 & 32.6 \\
\hline No & 291 & 67.4 \\
\hline \multicolumn{3}{|l|}{ Smoking } \\
\hline Yes & 63 & 14.6 \\
\hline No & 369 & 85.4 \\
\hline \multicolumn{3}{|l|}{ Alcohol } \\
\hline Yes & 3 & 0.7 \\
\hline No & 429 & 99.3 \\
\hline
\end{tabular}

SPM Sijil Pelajaran Malaysia, STPM Sijil Tinggi Persekolahan Malaysia

domain $(p<0.05$ and $p<0.001)$. This study found that respondents who practiced five times of obligatory prayers accompany with sunnah prayer had higher SF-36 mean score in all of SF-36 domain (ranging from 70.3 to 94.4) as compared to those who perform five times of obligatory prayers only (ranging from 40.5 to 74.7). 
Table 2 Percentage of elderly performing different religious activities $(\mathrm{N}=432)$

\begin{tabular}{lll}
\hline Religious activities & Frequency $(\mathrm{N})$ & Percentage $(\%)$ \\
\hline $\begin{array}{l}\text { Obligatory prayer } \\
5 \text { times with sunnah prayer }\end{array}$ & 330 & \\
5 times only or less & 102 & 76.4 \\
Midnight prayer & & 23.6 \\
Yes & 140 & 32.4 \\
No & 294 & 67.6 \\
Fasting & & \\
Yes & 129 & 29.9 \\
No & 303 & 70.1 \\
Recite Al-Quran daily & & \\
Yes & 298 & 69.0 \\
No & 134 & 31.0 \\
\hline
\end{tabular}

Similarly, respondents who practiced midnight prayer had higher SF-36 mean score in all of SF-36 domain (ranging from 69.9 to 94.7) as compared to those who did not (ranging from 52.7 to 85.7). However, the mean score difference between the two different group for midnight prayer activity was significant only for the domain of $\mathrm{PF}, \mathrm{RP}, \mathrm{VT}, \mathrm{SF}, \mathrm{RE}$, and $\mathrm{MH}(p<0.05$ and $p<0.001)$. Meanwhile, other religious activity such as fasting also showed a significant result. The mean score difference for SF-36 was significantly higher among the fasting group for all of SF-36 domain except for BP as depicted in Fig. 1. Additionally, significant result also can be seen between respondents who were reciting Al-Quran daily and respondents who were not for the domain of PF, RP, GH, and SF as represented in Fig. 2. Accordingly, this study had shown that elderly who practiced religious activities had higher SF-36

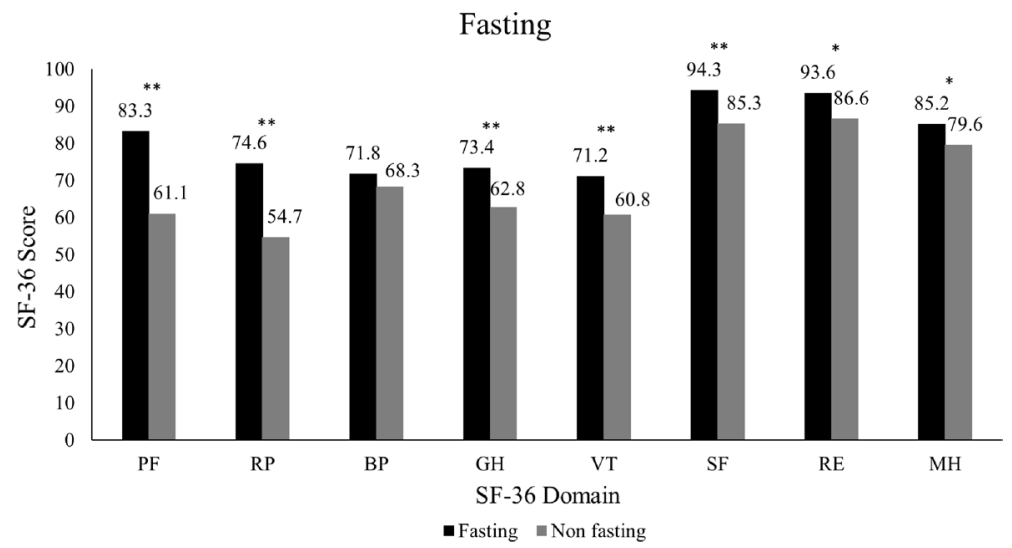

Fig. 1 Comparison of SF-36 mean score between fasting and non-fasting group. Caption: PF, physical functioning; RP, role limitations due to physical problem; BP, bodily pain; GH, general health perception; SF, social functioning; RE, role limitations due to emotional problems; VT, vitality; $\mathrm{MH}$, mental health. $* P$-value $<0.05, * * P$-value $<0.001$ 


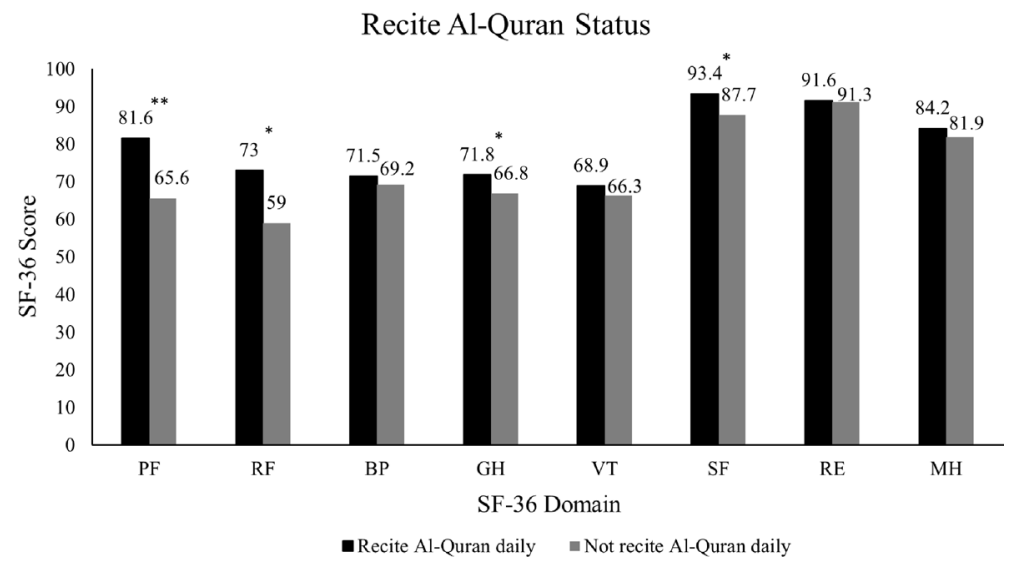

Fig. 2 Comparison of SF-36 mean score between recite Al-Quran daily and not recite Al-Quran daily group. Caption: PF, physical functioning; RP, role limitations due to physical problem; BP, bodily pain; $\mathrm{GH}$, general health perception; $\mathrm{SF}$, social functioning; RE, role limitations due to emotional problems; VT, vitality; $\mathrm{MH}$, mental health. $* P$-value $<0.05$, $* * P$-value $<0.001$

mean score in all domains compared to those who did not. Thus, higher SF-36 mean score indicated that elderly who practiced religious activities had better quality of life compared to those who did not.

Associations of the sociodemographic status with the GDS-15, OARS's IADL, and MoCA assessments also had been analyzed in this study. According to the results obtained (Table 3), it can be seen that respondents with medium to high income, who perform physical activity and had higher educational level, had statistically significant lower GDS-15 score and higher OARS's IADL and MoCA score compared to subjects with lower income, who did not perform physical activity and had lower educational level.

A logistic regression further was performed to ascertain the effects of socioeconomic level, educational level, and physical activity on the likelihood that respondents had depression (higher score of GDS-15), functional disability (lower OARS's IADL score), have cognitive impairment (lower MoCA score). From Table 4, physical activity status was significantly associated with all the assessments. However, the socioeconomic status was only significantly associated with OARS's IADL and MoCA assessment, while the educational level was only significantly associated with GDS-15 and MoCA assessment. These mean that participants who refused for tertiary education and did not perform physical activity tend to develop depression symptom (higher GDS-15 score) than participants who have tertiary education and perform physical activity. Furthermore, respondents with lower income and who did not perform physical activity tend to have functional disability (lower OARS's IADL score) than respondents with higher income and perform physical activity. Additionally, respondents from lower-income group, had lower educational level, and respondents who did not perform physical activity tend to have cognitive impairment (lower MoCA score) than respondents with higher income, higher educational level, and perform physical activity. 


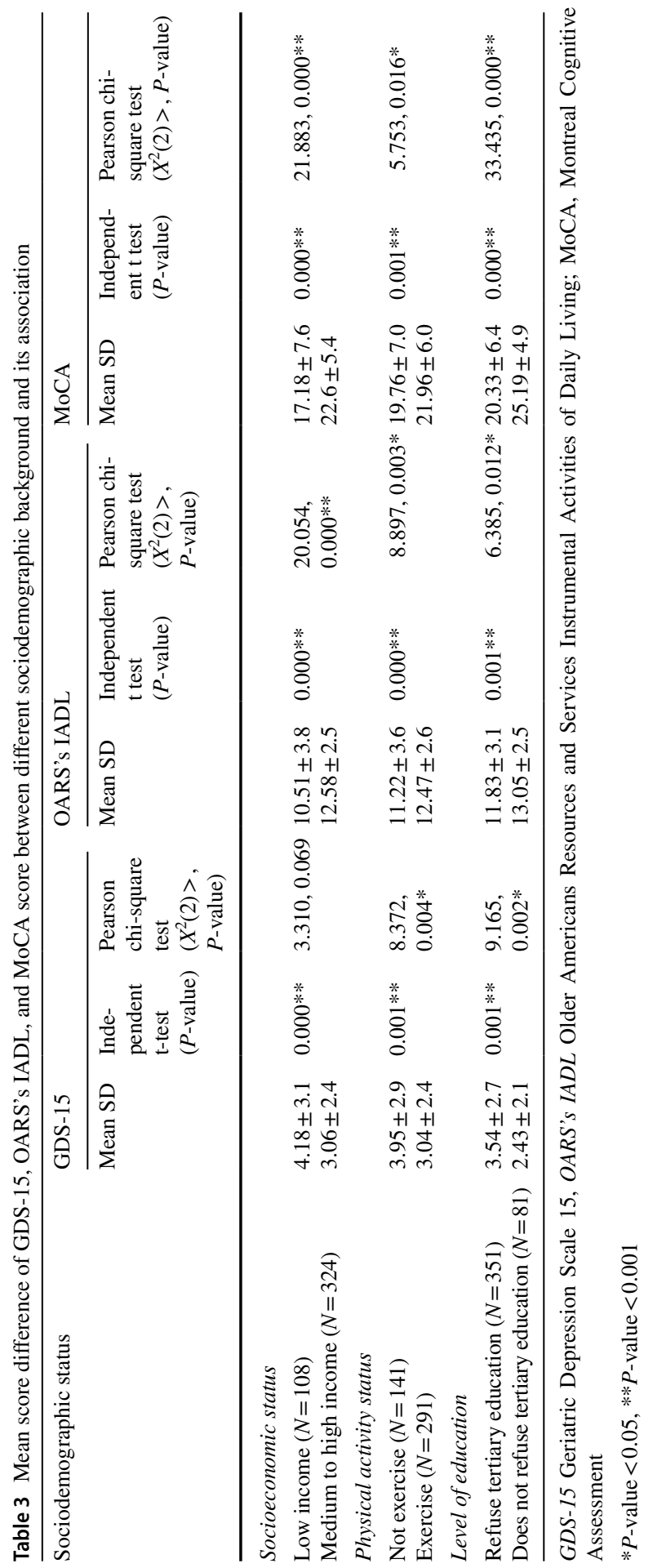


Table 4 Logistic regression of GDS-15, OARS's IADL, and MoCA score between different sociodemographic background

\begin{tabular}{|c|c|c|c|c|c|c|}
\hline \multirow[t]{2}{*}{ Sociodemographic status } & \multicolumn{2}{|c|}{ GDS-15 } & \multicolumn{2}{|c|}{ OARS's IADL } & \multicolumn{2}{|c|}{ MoCA } \\
\hline & OR & $P$-value, $95 \% \mathrm{CI}$ & OR & $P$-value, $95 \% \mathrm{CI}$ & OR & $\begin{array}{l}P \text {-value, } \\
95 \% \mathrm{CI}\end{array}$ \\
\hline \multicolumn{7}{|l|}{ Socioeconomic status } \\
\hline $\begin{array}{l}\text { Low income }(N=108) \\
\text { Medium to high income } \\
\qquad(N=324)\end{array}$ & 1.344 & $\begin{array}{l}0.249, \\
0.813,2.222\end{array}$ & 3.023 & $\begin{array}{l}0.000^{* *}, \\
1.715,5.329\end{array}$ & 2.729 & $\begin{array}{l}0.000 * *, \\
1.560,4.775\end{array}$ \\
\hline \multicolumn{7}{|l|}{ Physical activity status } \\
\hline $\begin{array}{l}\text { Not exercise }(N=141) \\
\text { Exercise }(N=291)\end{array}$ & 1.960 & $\begin{array}{l}0.004 * \\
1.236,3.109\end{array}$ & 2.335 & $\begin{array}{l}0.003^{*}, \\
1.346,4.049\end{array}$ & 1.761 & $\begin{array}{l}0.016 *, \\
1.114,2.786\end{array}$ \\
\hline \multicolumn{7}{|l|}{ Level of education } \\
\hline $\begin{array}{l}\text { Refuse tertiary education } \\
\quad(N=351) \\
\text { Does not refuse tertiary } \\
\text { education }(N=81)\end{array}$ & 2.753 & $\begin{array}{l}0.008 * \\
1.301,5.824\end{array}$ & 2.304 & $\begin{array}{l}0.095, \\
0.866,6.127\end{array}$ & 3.418 & $\begin{array}{l}0.000 * * \\
2.019,5.785\end{array}$ \\
\hline
\end{tabular}

GDS-15 Geriatric Depression Scale 15; OARS's IADL Older Americans Resources and Services Instrumental Activities of Daily Living, MoCA, Montreal Cognitive Assessment, OR, odds ratio, CI, confidence interval

$* P$-value $<0.05, * * P$-value $<0.001$

Table 5 Mean difference of GDS-15, IADL, and MoCA score between different religious activities among elderly

\begin{tabular}{|c|c|c|c|c|c|c|}
\hline \multirow[t]{2}{*}{ Religious Activities Status } & \multicolumn{2}{|l|}{ GDS-15 } & \multicolumn{2}{|l|}{ IADL } & \multicolumn{2}{|l|}{$\mathrm{MoCA}$} \\
\hline & Mean SD & $\begin{array}{l}\text { Inde- } \\
\text { pendent } \\
\text { t test }\end{array}$ & Mean SD & $\begin{array}{l}\text { Inde- } \\
\text { pendent } \\
\text { t test }\end{array}$ & Mean SD & $\begin{array}{l}\text { Inde- } \\
\text { pendent } \\
\text { t test }\end{array}$ \\
\hline \multicolumn{7}{|l|}{ Obligatory prayer } \\
\hline $\begin{array}{l}5 \text { times with sunnah prayer, } N=330 \\
5 \text { times only or less, } N=102\end{array}$ & $\begin{array}{l}2.9 \pm 2.1 \\
6.1 \pm 3.5\end{array}$ & $* *$ & $\begin{array}{l}12.8 \pm 1.9 \\
8.6 \pm 4.6\end{array}$ & $* *$ & $\begin{array}{l}22.8 \pm 4.9 \\
14.5 \pm 8.3\end{array}$ & $* *$ \\
\hline \multicolumn{7}{|l|}{ Midnight prayer } \\
\hline $\begin{array}{l}\text { Midnight prayer, } N=292 \\
\text { No midnight prayer, } N=140\end{array}$ & $\begin{array}{l}3.0 \pm 2.2 \\
4.1 \pm 3.2\end{array}$ & $* *$ & $\begin{array}{l}12.8 \pm 2.0 \\
10.5 \pm 4.0\end{array}$ & $* *$ & $\begin{array}{l}22.6 \pm 5.2 \\
18.5 \pm 7.8\end{array}$ & $* *$ \\
\hline \multicolumn{7}{|l|}{ Fast } \\
\hline $\begin{array}{l}\text { Fasting, } N=303 \\
\text { Not Fasting, } N=129\end{array}$ & $\begin{array}{l}2.8 \pm 2.1 \\
4.5 \pm 3.3\end{array}$ & $* *$ & $\begin{array}{l}12.9 \pm 2.1 \\
10.2 \pm 3.9\end{array}$ & $* *$ & $\begin{array}{l}22.6 \pm 5.4 \\
18 \pm 7.6\end{array}$ & $* *$ \\
\hline \multicolumn{7}{|l|}{ Al-Quran } \\
\hline $\begin{array}{l}\text { Reading Al-Quran daily, } N=298 \\
\text { Not Reading Al-Quran daily, } \\
\quad N=134\end{array}$ & $\begin{array}{l}3.1 \pm 2.4 \\
3.9 \pm 3.0\end{array}$ & $*$ & $\begin{array}{l}12.6 \pm 2.4 \\
10.8 \pm 3.7\end{array}$ & $* *$ & $\begin{array}{l}22.6 \pm 5.4 \\
18.2 \pm 7.4\end{array}$ & $* *$ \\
\hline
\end{tabular}

GDS-15 Geriatric Depression Scale 15, IADL Instrumental Activities of Daily Living, MoCA Montreal Cognitive Assessment

$* P$-value $<0.05 ; * * P$-value $<0.001$ 
Furthermore, the mean scores difference of GDS-15 was significant between different religious activity group as shown in Table 5 .

For obligatory prayers activity, the result showed that the group who practiced five times obligatory prayers with sunnah prayer had lower mean score of GDS-15 as compared to those who only perform five times or less of obligatory prayer. Similar results can be seen for other religious activities including practicing midnight prayer, fasting, and reciting Al-Quran. The results showed that those who practiced religious activities had lower mean score of GDS-15 as compared to those who did not (Table 5). Thus, lower GDS-15 among those who practiced religious activities indicated that the elderly in this group had better quality of life (no depression) compared to those who did not. Furthermore, the mean scores difference of OARS's IADL also was significant between different religious activity group. Similar pattern of results can be seen in OARS's IADL assessment whereby for obligatory prayer activity, higher mean score of OARS's IADL was found among those who practiced five times obligatory prayer with sunnah prayer as compared to those who practiced five times or less of obligatory prayer only. For other religious activities, the study had found higher mean score of OARS's IADL among those who were practicing midnight prayer, fasting, and reciting Al-Quran daily as compared to those who did not (Table 5).

Apart from this, assessment of cognitive function in this study was assessed by using MoCA and it was found that the mean score difference for MoCA was significantly higher among those who participated in religious activities (Table 5). The mean score of MoCA among all groups that practiced religious activities was higher compared to those who did not. Thus, this indicated that elderly who practiced religious activities had better cognitive function as compared to those who did not.

\section{Discussion}

Many studies are only focusing on the impacts of different levels of religion and spiritual involvement to the elderly's quality of life (Mat Saad et al., 2010). Unfortunately, studies on religions-related activities among elderly with their relation to the quality of life were still lacking (Koenig, 2012). Religious activities were mainly participated by the elderly; thus, they may have an influence on the elderly's quality of life and cognitive function (Ismail et al., 2012). Hence, this study evaluated the impact of practicing religious activities to the elderly's quality of life and cognitive function. Current study found that elderly who were highly engaged with the religious activities had better quality of life and cognitive function as compared to the elderly who were either less engaged or did not practice religious activities.

The SF-36 was commonly used to assess individual's quality of life. It was widely used in evaluating outcomes in different patient group and surveys (Zhu et al., 2016). The mean score of SF-36 was higher among those who were performing five times obligatory prayer with sunnah prayer, performing midnight prayer, fasting, and reciting Al-Quran. Additionally, this study also had found that practicing religious activities had a substantial positive impact on many measures specifically on all of the SF-36 domains. For instance, performing obligatory prayer either 
five times only or with sunnah prayer was associated with positive impact to the musculoskeletal system and flexibility through its repetitive ritual movements during the activity (Kamran, 2018). Besides that, prayers can influence individual's physiological functioning specifically balance by stimulating the visual, vestibular, and somatosensory systems that can influence human balance through sensory information provided (Alabdulwahab et al., 2013). Thus, it was believed that prayer can improve the elderly's physical fitness; hence, they can perform their daily activities without limitations in which it will indirectly give a positive effect in their quality of life. Therefore, this explains the higher score of all domain in SF-36 among those who performed five times obligatory prayer with sunnah prayer, specifically for the domain that assessed the ability of individuals to conduct daily activity which were PF, RP, VT, BP, and GH domain. Even though obligatory prayer was considered as a gentle and simple type of exercise, prayer also was found to have influence on the heart rate and blood pressure during its' long-time practice of meditation (Kamran, 2018; Osama \& Malik, 2019). Moreover, the author also explained that obligatory prayer involved continuous gentle muscle contraction and relaxation with perfect harmony and balance; thus, it was believed that obligatory prayer is able to enhance individual's mental health and emotions as represented in the current findings (Kamran, 2018).

This study also revealed that fasting does not impact the elderly's quality of life entirely, but it can affect on the physical functioning, social functioning, role physical, role emotional, mental health, vitality, and general health. Previous study also found that elderly who practiced intermittent Monday and Thursday fasting accompanied with restrictive diet do not improve the quality of life wholly, but it can improve the vitality and the perceptions of physical health (Teng et al., 2011). Another study found that time-restricted feeding (TRF), a form of intermittent fasting, was shown to have a positive impact on physical functioning of overweight older adults specifically in walking speed (Anton et al., 2019). Additionally, previous study showed that fasting was proven to be beneficial for the physical health specifically in lowering the risk of vascular dysfunction, cardiovascular disease, and insulin resistance (Golbidi et al., 2017). Hence, it was thought that the cumulative benefits of fasting to individual's health may contribute to the substantial positive impact on many qualities of life measures specifically on SF-36 domain of PF, RP, VT, and GH. Besides, current study revealed that reciting Al-Quran was found to have a positive impact to the individuals specifically for the domain of PF, RP, GH, and SF. Throughout the literature, almost all of the studies found the positive impact of reciting Al-Quran to individual's emotion and mental health, but not directly explain the impact of reciting Al-Quran to physical functioning of the elderly. In some studies, it was noted that Al-Quran memorization can lead the memorizers to a better mental health state, particularly in the area of anxiety, sleep disorders, depression, and social function (Kimiaee et al., 2012). However, previous study stated that Malay elderly women tend to get to be socialized with others through attending informal classes on how to recite Al-Quran and teaching others to recite Al-Quran correctly conducted at nearby surau and mosque (Minhat, 2014). This can actually enhance their social functioning and develop strong social support network. It is also believed that they will be more physically active through actively involved in 
this religious activity with the community, resulting in better impact on their physical functioning and role physical. Additionally, recitation of Al-Quran was usually done with various tarannum or song/melody (Nayef \& Wahab, 2018). Thus, sound therapy through listening to melodious Al-Quran recitations can serve as an antidote and/or a healer (Nayef \& Wahab, 2018; Tumiran et al., 2013). Consequently, this will help the elderly to always feel positive toward their general health as presented in the current findings.

Depression is a frequent psychiatric dispute among elderly. However, it was underrecognized as the symptoms sometimes may be overlapping with the limitations that they had due to aging (Mohd Aznan et al., 2019). In this study, the GDS15 score was also taken as a part of quality of life study. This is because depression was associated with lower SF-36 score compared to normal population (Verma et al., 2010). Hence, the absence of depressive symptoms is important to the elderly to have a better quality of life. From this study, it can be seen that respondents who had higher income, higher educational level, and perform physical activity had lower GDS-15 score. Previous local study by Shahar et al. (2019) also found that low socioeconomic status subjects tend to have higher GDS-15 score compared to medium to high socioeconomic status in urban living elderlies. A study in Myanmar had proven that depressive symptoms in older adults were strongly associated with lower economic status (AOR: 4.18, 95\% CI: 2.98-5.87) (Yamada, Yoshikawa $\&$ Matsushima, 2020). Poor socioeconomic status has been linked to a lack of access to mental health services, which has a negative impact on the diagnosis and treatment of depression, since it is extremely difficult for low-income people to maintain regular healthcare requirements and be checked for depressed symptoms (Fang et al., 2019; $\mathrm{Ng}$ et al., 2014). However, this study found that there was no association between socioeconomic status and GDS-15 assessment, but there was a significant association of GDS-15 assessment with physical activity status and level of education. Recent study conducted among older people suffered from COVID-19 found that participants who engaged in higher levels of physical exercise had less depression-like symptoms (Callow et al, 2020). Many studies showed similar results (Mura \& Carta, 2013; Pinheira et al., 2018), and Kvæl et al. (2017) suggested to promote physical exercise to protect against end-of-life depression, underscoring the relevance of physical exercise for the elderly. Also, a study by Kim et al. (2013) found that there was a significant association between education level and individual GDS score. Based on the study, they had found that the patients with high school $(p=0.0441)$ and university diploma $(p=0.0004)$ had significantly lower GDS scores than those patients without high school diploma (Kim et al., 2013). Kate et al. (2017) explained that educational level can trigger the depression symptoms due to factors such as low cultural entitlement, household income, job insecurity, and embeddedness in neighborhood.

The GDS-15 scores of all respondents were also compared between two different groups of elderly based on their level of religious activities participation. The results showed that the score was lower among elderly who participated in the religious activities. This finding was in line with the previous studies that proved the benefits of practicing religious activities in lowering the depressing symptoms (Osama $\&$ Malik, 2019). Praying had shown positive outcomes among psychiatric disorders 
such as lowering the post-hospitalization depression. Praying was suggested as an alternative therapy for psychiatric disorders in view the benefit outcome of praying was similar with other alternative therapies such as meditation, exercise, or herbal treatments (Sabry \& Vohra, 2013). In detail, praying may help someone to feel extreme connection with the God (who is the only one that has the power of controlling the world) and believe that the God is the one who can provide maximum support. Thus, these feelings may impact on someone's mental health positively (Sabry \& Vohra, 2013). Not only prayers, reciting and listening to the AlQuran as well can produce a sense of relaxation (Mahjoob et al., 2016). Al-Quran recitation may affect on the human heart causing some hormones and chemical that were responsible for relaxation to be affected (Nayef \& Wahab, 2018). Many studies highlighted the beautiful and attractive sound of Al-Quran recitation that may influenced someone's emotions in a positive way as concluded in the research work done by Nayef and Wahab (2018). Moreover, it is believed that religious activities may help to strengthen someone's spirituality and thus improve someone's mental health. A randomized clinical trial study had found that Islamic spiritual program had improved the elderly's attitude toward and interpretation of life. The study highlighted the importance of spirituality in helping the elderly to see their life in more meaningful way despite their illness and despair, thus improving their mental health (Moeini et al., 2016). Additionally, fasting had shown many positive impacts on elderly's mental health including anxiety, insomnia, and depression. Recent study by Ghazi et al. (2018) found that there was a significant improvement on anxiety, insomnia, and severe depression among elderly after the Ramadan fasting. This positive outcome may be due to the improvement that can be seen in the elderly in terms of their spiritual and religious feelings during Ramadan as the result from the social support, promotion of positive feelings (as optimism and perceived control), thus creating a meaningful purpose in their life (Ghazi et al., 2018). Hence, all of these explain the relatively low GDS-15 score among elderly who highly practiced in religious-related activities.

Assessment of OARS's IADL was also being done in this study to further elaborate the status of the elderly's quality of life in view good quality of life encompasses optimum daily living function to achieve satisfactions in life (Barcaccia et al., 2013). This study showed that respondents with medium to high income, who perform physical activity, and had higher educational level tend to have higher OARS's IADL score. However, only socioeconomic status and physical activity status were significantly associated with OARS's IADL assessment. Good economic status was found to be the protective factors of functional status of respondents in China (Zhong et al., 2017). A cross-sectional study in Brazil also found that older women from lower socioeconomic groups had a higher level of impairment (Veiga et el., 2016; Shahar et al., 2019). Similarly, Hamada et al. (2019) found that low-income older persons were more likely to be functionally dependent. In terms of physical activity status, a study found that older people who did not meet minimal requirement for aerobic physical activity had significantly more problem with their IADLs (Crevenna \& Dorner, 2019). Similar finding was also found in China whereby lower physical activity was found among older people living in urban areas in Liaoning Province of China, and they tend to have lower IADL score (Wang et al., 2019). 
Majority in the literature suggest the elderly to perform or increase physical activity in order to improve their performance status and functions in daily life (Crevenna \& Dorner, 2019; Wang et al., 2019). A study suggested that one of the important types of physical activity for elderly to improve IADL of elderly was walking activity as it can help in maintaining the motor functions as well as encourage participation in the community (Tsai et al., 2013).

This study also showed that the OARS's IADL score was higher among elderly who performed religious activities as compared to the opposite group. The combination of good physical and mental health that was brought by the religious activities has made the optimum daily living possible. In such, current study showed that elderly who performed five times obligatory prayers accompanied with sunnah prayer had higher OARS's IADL scores than the group who only performed 5 times or less obligatory prayer. Similar findings can be seen among the group who performed midnight prayer who are also had higher OARS's IADL scores than who did not performed the activity. The reason for this was thought to be the fact that performing prayer involves several movements of the body specifically the lower part of the body. Hence, the more an individual performed prayers, the more will the body had to move, creating more body strength especially at the leg part. Leg strength and level of physical activity can serve as indicators for elderly's balance, mobility function, and ability to live independently. This statement can be proven by previous study done by Yüksek (2017) who found that the physical fitness level of the elderly men who performed prayer was higher than those who were sedentary, and the study also showed that the leg strength among the prayer-performing group was higher than the sedentary group. This was because the ritual of performing prayers involves several movements of the body which include 40 repetitions of rükü and 80 repetitions of bowing and standing up over five daily prayer sessions which can serve as a form of exercise that positively affects the leg strength of the elderly (Yüksek, 2017). Thus, the more an individual pray, the more will the body build up the strength, resulting the elderly to be able to perform their daily activity independently. Furthermore, current study also found that elderly who fast had higher OARS's IADL score compared to those who did not. A study showed that alternate day fasting can help in reducing individual's weight by $4.5 \%$ and improves the fatto-lean ratio (Stekovic et al., 2019). Maintaining healthy weight and lean muscle were very important among elderly as obese elderly were found to have limitations to perform daily living activity (Drumond Andrade et al., 2013). Thus, it is believed that elderly who routinely fast will have better weight management; therefore, they can conduct their daily living activity easily.

MoCA was used in this study to assess the cognitive function of the respondents. This study showed that respondents with medium to high income, perform physical activity, and had higher educational level tend to have higher MoCA score. All of these sociodemographic statuses showed a significant correlation with the MoCA assessment. For socioeconomic factor, recent local study also found similar finding whereby respondents from low income had significantly lower cognitive performances (Shahar et al., 2019). This was likely due to the unhealthy lifestyle of the people living in urban areas in which they had higher likelihood to adopt Westernized lifestyle. Their dietary pattern that was high in 
fat and sugar accompanied with sedentary lifestyle contributed to the risk of poor cognitive function (Shahar et al., 2019; Xu et al., 2017). For physical activity status, other study found similar finding (Woodard et al., 2012) whereby physical activity was found to be associated with larger brain volumes (fewer brain atrophy) specifically in brain regions vulnerable to dementia, comprising the hippocampus, temporal, and frontal regions based on the results from structural magnetic resonance imaging (MRI) (Domingos, Pego, \& Santos, 2021). Next, for educational factor, this study found that respondents who do not refuse tertiary education (higher educational level) had statistically significant higher MoCA score as compared to those who refuse tertiary education (lower educational level). This finding was consistent with other study whereby education was revealed to be a protective factor against the negative effects of depressive mood on memory in elderly women (Lee et al., 2018). Education can help to promote cognitive reserve by keeping the brain active and neurons were engaged. Obtaining a greater degree of cognitive reserve is the outcome of receiving adequate education and engaging in cognitive activities (Lee et al., 2018).

Current study found that MoCA score of the elderly in the religious activities participating group was higher compared to the elderly in the non-religious activities participating group. This finding was in line with the recent systemic review findings done by Hosseini et al. (2019) whereby the authors had found that religious/spiritual involvement was important in protecting the middle- and old-age adults against cognitive decline. Most of the literatures supported the positive association between religious/spiritual involvement and cognitive function (Hosseini et al., 2019). This can be explained by the multiple aspects of religious activities that involve continuous stimulation of the brain such as recitation and reciting verses of Al-Quran, focus during performing prayers, and also motor function with repetitive sequence of activities (Hosseini et al., 2019). For instance, daily prayer has been shown to have the ability to improve cognitive functioning among the elderly in view prayer requires concentration and combines elements of physical exercise (Norsiah \& Nurul Amira, 2017). Moreover, the careful attention to listening and pronunciation of Al-Quran verses stimulates an area of the brain in the temporal lobe which is the center of memory consolidation when learning Al-Quran (Rani et al., 2019). Besides that, Al-Quran recitation is expected to have the ability to improve on speech, learning, and interpersonal relationship (Tumiran et al., 2013). The audible beauty of Al-Quran will make the listener to feel the hypnotic emotional and the beautiful effect of it, which can be used as part of the sound therapy for almost all individuals. Sound therapy has been used to overcome various health problems including depression, emotional and psychological problems, traumatic brain injury, and stroke recovery (Rani et al., 2019; Nayeb \& Wahab, 2018). Hence, all these activities explain the relatively high MoCA score among elderly who were highly engaged in religious-related activities. Therefore, it can be seen that elderly who were highly engaged in religious activities had better cognitive function and they were more likely to have a better quality of life.

Although this study has revealed a significant result, the information given was mainly concentrated on the impact of the selected religious practices only. Therefore, more details on the impact of other religious practices such as sunnah eating 
practices may give more in-depth information on the impact of religious practices to the elderly's quality of life and cognitive function, entirely.

\section{Conclusion}

In a nutshell, there was a significant impact on the quality of life and cognitive function among elderly practicing religious activities. However, this study also found that other sociodemography factors such as socioeconomic status, physical activity status, and educational level were associated with the GDS-15, OARS's IADL, and MoCA score. Nevertheless, the elderlies who were remarkably engaged with the religious activities had better quality of life and cognitive function as compared to those elderly who were either less engaged or did not practice religious activities. It was highlighted that quality of life needs to be approached holistically which were in terms of mental health and physical health. This study had proven that religious activities had a positive impact and benefits to the elderly's health and well-being, especially on their quality of life and cognitive functioning. This can eventually create awareness toward this population on the importance of practicing and involve in religious activities in order to achieve healthy aging. However, further studies are recommended to explore about other religious activities and their relationship with quality of life and cognitive function.

Acknowledgements Appreciation goes to all the respondents for their cooperation, support, and contribution to this study.

Author Contributions All authors contributed to the study conception and design. Material preparation, data collection, and analysis were performed by SNA, AHQAT, FA, and IZS. The first draft of the manuscript was written by SNA, and all authors commented on previous versions of the manuscript. All authors read and approved the final manuscript.

Funding This work was financially supported by Universiti Sains Islam Malaysia Grant (USIM/UKM/ RCRP/FPSK/052002/71017).

Availability of Data and Material Due to the nature of this research, participants of this study did not agree for their data to be shared publicly, so supporting data are not available.

Code Availability Not applicable.

\section{Declarations}

Conflict of interest The authors declare that they have no conflict of interest.

Ethical Approval The procedure involved in this study was approved by the Research Ethics Committee of Universiti Sains Islam Malaysia and certified that the study was performed in accordance with the ethical standards as laid down in the 1964 Declaration of Helsinki and its later amendments or comparable ethical standards.

Consent to Participate Informed consent was obtained from all individual participants included in the study. 


\section{References}

Alabdulwahab, S. S., Kachanathu, S. J., \& Oluseye, K. (2013). Physical activity associated with prayer regimes improves standing dynamic balance of healthy people. Journal of Physical Therapy Science, 25, 1565-1568. https://doi.org/10.1589/jpts.25.1565

Anton, S. D., Lee, S. A., Donahoo, W. T., McLaren, C., Manini, T., Leeuwenburgh, C., \& Pahor, M. (2019). The effects of time restricted feeding on overweight, older adults: A pilot study. Nutrients, 11, 1500. https://doi.org/10.3390/nu11071500

Aznan, M. A. M., Mohamad, C. M., Suriati, S. N., \& Zubir, Y. M. (2019). Prevalence of depressive symptoms among elderly and its predictors: A cross sectional study in community Felda Bukit Goh, Kuantan Pahang. Journal of Family Medicine Forecast, 2, 1-6.

Barcaccia, B., Esposito, G., Matarese, M., Bertolaso, M., Elvira, M., \& De Marinis, M. G. (2013). Defining quality of life: A wild-goose chase? Europe's Journal of Psychology, 9, 185-203. https://doi.org/10.5964/ejop.v9i1.484

Callow, D. D., Arnold-Nedimala, N. A., Jordan, L. S., Pena, G. S., Won, J., Woodard, J. L., \& Smith, J. C. (2020). The mental health benefits of physical activity in older adults survive the COVID19 pandemic. The American Journal of Geriatric Psychiatry: Official Journal of the American Association for Geriatric Psychiatry, 28, 1046-1057. https://doi.org/10.1016/j.jagp.2020.06.024

Crevenna, R., \& Dorner, T. E. (2019). Association between fulfilling the recommendations for healthenhancing physical activity with (instrumental) activities of daily living in older Austrians. Wiener Klinische Wochenschrift, 131, 265-272.

Department of Statistics Malaysia (2011). Population distribution and basic demographic characteristic report 2010. https://www.dosm.gov.my/v1/index.php?r=column/ctheme\&menu_id=L0phe U43NWJwRWVSZklWdzQ4TlhUUT09\&bul_id=MDMxdHZjWTk1SjFzTzNkRXYzcVZjdz09.

Domingos, C., Pêgo, J. M., \& Santos, N. C. (2021). Effects of physical activity on brain function and structure in older adults: A systematic review. Behavioural Brain Research, 402, 113061.

Dominguez, J. C., Orquiza, M. G., Soriano, J. R., Magpantay, C. D., Esteban, R. C., Corrales, M. L., \& Ampil, E. R. (2013). Adaptation of the montreal cognitive assessment for elderly filipino patients. East Asian Archives of Psychiatry: Official Journal of the Hong Kong College of Psychiatrists, 23, 80-85.

Department of Statistics Malaysia, DOSM. (2018). Department of Statistics Malaysia press release. https://doi.org/10.1017/CBO9781107415324.004.

Drumond Andrade, F. C., Mohd Nazan, A. I., Lebrão, M. L., \& de Oliveira Duarte, Y. A. (2013). The impact of body mass index and weight changes on disability transitions and mortality in Brazilian older adults. Journal of Aging Research. https://doi.org/10.1155/2013/905094

Fang, M., Mirutse, G., Guo, L., \& Ma, X. (2019). Role of socioeconomic status and housing conditions in geriatric depression in rural China: A cross-sectional study. BMJ Open, 9, e024046.

Fillenbaum, G. G., \& Smyer, M. A. (1981). The development, validity, and reliability of the OARS multidimensional functional assessment questionnaire. Journal of Gerontology, 36(4), 428-434. https://doi.org/10.1093/geronj/36.4.428

Ghazi, H. A., Boughdady, A. M., \& Elsayed, E. B. M. (2018). Effect of Ramadan fasting on physical and mental health of elderly people. World Journal of Nursing Sciences, 4, 56-65. https://doi. org/10.5829/idosi.wjns.2018.56.65

Golbidi, S., Daiber, A., Korac, B., Li, H., Essop, M. F., \& Laher, I. (2017). Health benefits of fasting and caloric restriction. Current Diabetes Reports, 17, 123. https://doi.org/10.1007/ s11892-017-0951-7

Greenberg, S. A. (2019). The Geriatric Depression Scale (GDS): Issue 4 general assessment series. https://hign.org/consultgeri/try-this-series/geriatric-depression-scale-gds.

Hall, S., Opio, D., Dodd, R. H., \& Higginson, I. J. (2011). Assessing quality of life in older people in care homes. Age and Ageing, 40, 507-512. https://doi.org/10.1093/ageing/afr027

Hamada, S., Takahashi, H., Sakata, N., Jeon, B., Mori, T., Iijima, K., Yoshie, S., Ishizaki, T., \& Tamiya, N. (2019). Household income relationship with health services utilization and healthcare expenditures in people aged 75 years or older in japan: A population-based study using medical and longterm care insurance claims data. Journal of Epidemiology, 29, 377-383.

Harada, C. N., Natelson Love, M. C., \& Triebel, K. L. (2013). Normal cognitive aging. Clinics in Geriatric Medicine, 29, 737-752. https://doi.org/10.1016/j.cger.2013.07.002 
Harith, S., \& Tan, S. L. (2020). Translation and validation of the malay version of comprehensive geriatric assessment questionnaire for older adults in Malaysia. Annals of Geriatric Medicine and Research, 24(2), 115-124. https://doi.org/10.4235/agmr.20.0005

Hosseini, S., Chaurasia, A., \& Oremus, M. (2019). The effect of religion and spirituality on cognitive function: A systematic review. The Gerontologist, 59, e76-e85. https://doi.org/10.1093/geront/ gnx 024

Ismail, Z., Ibrahim, W., \& Baharuddin, E. (2012). Religious participations among the older persons in Malaysia. Advances in Natural and Applied Sciences, 6, 388-391.

Kamran, G. (2018). Physical benefits of (Salah) prayer - Strengthen the faith \& fitness. Journal of Novel Physiotherapy and Rehabilitation, 2, 043-053. https://doi.org/10.29328/journal.jnpr.1001020

Kate, J., Koster, W., \& Waal, J. (2017). Why are depressive symptoms more prevalent among the less educated? The relevance of low cultural capital and cultural entitlement. Sociological Spectrum, 37(2), 63-76.

Kim, E., Kim, H., Park, Y., Park, C., Yu, D., \& Lee, J. Y. (2013). Prevalence and risk factors of depression in geriatric patients with dermatological diseases. Annals of Dermatology, 25, 278-284.

Kimiaee, S. A., Khademian, H., \& Farhadi, H. (2012). Quran memorization and its effect on the elements of mental health. Sociology of Women (Journal of Woman And Society), 2, 1-20.

Koenig, H. G. (2012). Religion, spirituality, and health: The research and clinical implications. ISRN Psychiatry, 2012, 278730. https://doi.org/10.5402/2012/278730

Kvæl, L., Bergland, A., \& Telenius, E. W. (2017). Associations between physical function and depression in nursing home residents with mild and moderate dementia: a cross-sectional study. BMJ Open, 7 , e016875.

Lee, J., Park, H., \& Chey, J. (2018). Education as a protective factor moderating the effect of depression on memory impairment in elderly women. Psychiatry Investigation, 15, 70-77.

Mahjoob, M., Nejati, J., Hosseini, A., \& Bakhshani, N. M. (2016). The effect of holy Quran voice on mental health. Journal of Religion and Health, 55, 38-42. https://doi.org/10.1007/s10943-014-9821-7

Malone, J., \& Dadswell, A. (2018). The role of religion, spirituality and/or belief in positive ageing for older adults. Geriatrics (Basel, Switzerland), 3, 28. https://doi.org/10.3390/geriatrics3020028

Mat Saad, Z. M., Hatta, Z. A., \& Mohamad, N. (2010). The impact of spiritual intelligence on the health of the elderly in Malaysia. Asian Social Work and Policy Review, 4, 84-97. https://doi.org/10.1111/j. 1753-1411.2010.00039.x

Minhat, H. (2014). Why Malay elderly female frequently engaged in religious activities during leisure?: A qualitative approach in Selangor. Malaysian Journal of Public Health Medicine, 14, 39-46.

Moeini, M., Sharifi, S., \& Zandiyeh, Z. (2016). Does Islamic spiritual program lead to successful aging? A randomized clinical trial. Journal of Education and Health Promotion, 5, 1-7. https://doi.org/10. 4103/2277-9531.184561

Mura, G., \& Carta, M. G. (2013). Physical activity in depressed elderly. A systematic review. Clinical Practice and Epidemiology in Mental Health, 9, 125-135.

Nasreddine, Z. S., Phillips, N. A., Bédirian, V., Charbonneau, S., Whitehead, V., Collin, I., Cummings, J. L., \& Chertkow, H. (2005). The montreal cognitive assessment, MoCA: A brief screening tool for mild cognitive impairment. Journal of the American Geriatrics Society, 53, 695-699. https://doi. org/10.1111/j.1532-5415.2005.53221.x

Nayef, E. G., \& Wahab, M. N. A. (2018). The effect of recitation Quran on the human emotions. International Journal of Academic Research in Business and Social Sciences, 8, 50-70. https://doi.org/10. 6007/IJARBSS/v8-i2/3852

Ng, C. W., Tan, W. S., Gunapal, P. P. G., Wong, L. Y., \& Heng, B. H. (2014). Association of socioeconomic status (ses) and social support with depressive symptoms among the elderly in Singapore. Annals Academy of Medicine, 43, 576-587.

Norsiah, F., \& Nurul Amira, A. (2017). The effects of neurotherapy (NFT) using Ayatul Kursi as stimulus on memory performance. Journal of Islamic, Social, Economics and Development, 2, 22-32.

Osama, M., \& Malik, R. (2019). Activation of the trunk muscles during Salat (Muslim Prayer). Journal of the Pakistan Medical Association, 69, 1929. https://doi.org/10.5455/JPMA.33-1553667415

Perry, W., Lacritz, L., Roebuck-Spencer, T., Silver, C., Denney, R. L., Meyers, J., McConnel, C. E., Pliskin, N., Adler, D., Alban, C., Bondi, M., Braun, M., Cagigas, X., Daven, M., Drozdick, L., Foster, N. L., Hwang, U., Ivey, L., Iverson, G., ... Golden, T. (2018). Population health solutions for assessing cognitive impairment in geriatric patients. The Clinical Neuropsychologist, 32, 11931225. https://doi.org/10.1080/13854046.2018.1517503 
Pinheira, V., Alves, D., \& Pires, M. (2018). the relationship between mobility, physical activity and strength with depression, cognitive state and health status in the elderly in Portugal. The European Journal of Social \& Behavioural Sciences, 23, 2753-2768.

Prince, M., Comas-Herrera, A., Knapp, M., Guerchet, M., \& Karagiannidou, M. (2016). World Alzeheimer Report 2016: Improving healthcare for people living with dementia: Coverage, quality and costs now in the future. https://www.alz.co.uk/research/WorldAlzheimerReport2016.pdf.

Rani, M. D. M., Ithnin, M., Nor, N. A. U. M., Juliana, N., Effendy, N. M., Azmani, S., Abdullah, K. H. A., Aris, M. S. M., \& Abu, I. F. (2019). Comparison of health-seeking behaviour between urban and rural Malay population of Negeri Sembilan, Malaysia. International Journal of Research in Pharmaceutical Sciences, 10, 3608-3615. https://doi.org/10.26452/ijrps.v10i4.1742

Sabry, W. M., \& Vohra, A. (2013). Role of Islam in the management of psychiatric disorders. Indian Journal of Psychiatry, 55, S205-S214. https://doi.org/10.4103/0019-5545.105534

Sararaks, S., Azman, A. B., Low, L. L., Rugayah, B., Aziah, A. M., Hooi, L. N., Razak, M. A., Norhaya, M. R., Lim, K. B., Azian, A. A., \& Geeta, S. (2005). Validity and reliability of the SF-36: The Malaysian context. Medical Journal of Malaysia, 60, 163-179.

Sayeed, S. A., \& Prakash, A. (2013). The Islamic prayer (Salah/Namaaz) and yoga togetherness in mental health. Indian Journal of Psychiatry, 55, S224-S230. https://doi.org/10.4103/0019-5545.105537

Shahar, S., Vanoh, D., Mat Ludin, A. F., Singh, D. K. A., \& Hamid, T. A. (2019). Factors associated with poor socioeconomic status among Malaysian older adults: An analysis according to urban and rural settings. BMC Public Health, 19, 1-12.

Stekovic, S., Hofer, S. J., Tripolt, N., Aon, M. A., Royer, P., Pein, L., Stadler, J. T., Pendl, T., Prietl, B., Url, J., Schroeder, S., Tadic, J., Eisenberg, T., Magnes, C., Stumpe, M., Zuegner, E., Bordag, N., Riedl, R., Schmidt, A., ... Madeo, F. (2019). Alternate day fasting improves physiological and molecular markers of aging in healthy, non-obese humans. Cell Metabolism, 30, 462-476.e6. https:// doi.org/10.1016/j.cmet.2019.07.016

Teeters, D. A., Moua, T., Li, G., Kashyap, R., Biehl, M., Kaur, R., Gajic, O., Boeve, B. F., St Louis, E. K., Petersen, R. C., \& Caples, S. M. (2016). Mild cognitive impairment and risk of critical illness. Critical Care Medicine, 44, 2045-2051. https://doi.org/10.1097/CCM.0000000000001842

Teng, N. I., Shahar, S., Manaf, Z. A., Das, S. K., Taha, C. S., \& Ngah, W. Z. (2011). Efficacy of fasting calorie restriction on quality of life among aging men. Physiology \& Behavior, 104, 1059-1064. https://doi.org/10.1016/j.physbeh.2011.07.007

Tsai, L. T., Rantakokko, M., Portegijs, E., Viljanen, A., Saajanaho, M., Eronen, J., \& Rantanen, T. (2013). Environmental mobility barriers and walking for errands among older people who live alone vs. with others. BMC Public Health, 13, 1054

Tumiran, M. A., Mohamad, S. P., Saat, R. M., Yusoff, M. Y. Z. M., Rahman, N. N. A., \& Adli, D. S. H. (2013). Addressing sleep disorder of autistic children with Qur'anic sound therapy. Health, 5, 73-79. https://doi.org/10.4236/health.2013.58A2011

van Leeuwen, K. M., van Loon, M. S., van Nes, F. A., Bosmans, J. E., de Vet, H., Ket, J., Widdershoven, G., \& Ostelo, R. (2019). What does quality of life mean to older adults? A thematic synthesis. Plos One, 14, e0213263. https://doi.org/10.1371/journal.pone.0213263

Veiga, B., Pereira, R. A., Pereira, A. M., \& Nickel, R. (2016). Evaluation of functionality and disability of older elderly outpatients using the WHODAS 2.0. Revista Brasileira de Geriatria e Gerontologia, 19, 1015-1021.

Verma, S. K., Luo, N., Subramaniam, M., Sum, C. F., Stahl, D., Liow, P. H., \& Chong, S. A. (2010). Impact of depression on health related quality of life in patients with diabetes. Annals of the Academy of Medicine Singapore, 39, 913-917.

Wang, B., Wu, Y., Zhang, T., Han, J., Yu, L., \& Sun, W. (2019). Effect of physical activity on independent living ability among community-dwelling elderly in urban areas of Liaoning Province in China: A population-based study. British Medical Journal Open, 9(e023543), 1-8.

Wang, H. X., Xu, W., \& Pei, J. J. (2012). Leisure activities, cognition and dementia. Biochimica Et Biophysica Acta, 1822, 482-491. https://doi.org/10.1016/j.bbadis.2011.09.002

Woodard, J. L., Sugarman, M. A., Nielson, K. A., Smith, J. C., Seidenberg, M., Durgerian, S., Matthews, M. A., \& Rao, S. M. (2012). Lifestyle and genetic contributions to cognitive decline and hippocampal structure and function in healthy aging. Current Alzheimer Research, 9, 436-446.

World Health Organization, WHO. (2018). Ageing and health. https://www.who.int/news-room/factsheets/detail/ageing-and-health.

Xu, H., Dupre, M. E., Gu, D., \& Wu, B. (2017). The impact of residential status on cognitive decline among older adults in China: Results from a longitudinal study. BMC Geriatrics, 17, 107. 
Yamada, H., Yoshikawa, K., \& Matsushima, M. (2020). Geriatric depressive symptoms in Myanmar: Incidence and associated factors. Journal of Applied Gerontology, 39(11), 1230-1239. https://doi. org/10.1177/0733464819879605

Yüksek, S. (2017). The effects of performing prayer on the physical fitness levels of men over 60 years old. Journal of Education and Training Studies, 5, 56-63. https://doi.org/10.11114/jets.v5i11.2641

Zhong, Y., Wang, J., \& Nicholas, S. (2017). Gender, childhood and adult socioeconomic inequalities in functional disability among Chinese older adults. International Journal for Equity in Health, 16, 165.

Zhu, Y. X., Li, T., Fan, S. R., Liu, X. P., Liang, Y. H., \& Liu, P. (2016). Health-related quality of life as measured with the Short-Form 36 (SF-36) questionnaire in patients with recurrent vulvovaginal candidiasis. Health and Quality of Life Outcomes, 14, 65. https://doi.org/10.1186/s12955-016-0470-2

Publisher's Note Springer Nature remains neutral with regard to jurisdictional claims in published maps and institutional affiliations.

\title{
Authors and Affiliations
}

\section{Syazwan Nazri Amir ${ }^{1}$. Norsham Juliana ${ }^{1}$ (D) Sahar Azmani ${ }^{1}$. Izuddin Fahmy Abu' ${ }^{2}$ Abd Hafiz Qayyum Abd Talib ${ }^{2}$. Farahin Abdullah ${ }^{2}$. Intan Zulaikha Salehuddin ${ }^{2}$. Nur Islami Mohd Fahmi Teng ${ }^{3}$. Nur Azma Amin ${ }^{2}$. Nor Amira Syahira Mohd Azmi ${ }^{1}$ Nur Adilah Shuhada Abd Aziz ${ }^{1}$}

\author{
Syazwan Nazri Amir \\ amirulirshad@yahoo.com \\ Sahar Azmani \\ drazmanisahar@usim.edu.my \\ Izuddin Fahmy Abu \\ izuddin@unikl.edu.my \\ Abd Hafiz Qayyum Abd Talib \\ qayyumtalib.qshe@gmail.com \\ Farahin Abdullah \\ a.farahin7@gmail.com \\ Intan Zulaikha Salehuddin \\ intanz.salehuddin@gmail.com \\ Nur Islami Mohd Fahmi Teng \\ nurislami@uitm.edu.my
}

Nur Azma Amin

nurazma@unikl.edu.my

Nor Amira Syahira Mohd Azmi amirasyahira188@gmail.com

Nur Adilah Shuhada Abd Aziz nradilahaziz@gmail.com

1 Faculty of Medicine and Health Sciences, Universiti Sains Islam Malaysia, Nilai, Negeri Sembilan, Malaysia

2 Institute of Medical Science Technology, Universiti Kuala Lumpur, 43000 Kajang, Malaysia

3 Faculty of Health Sciences, Universiti Teknologi MARA Cawangan Selangor, 42300 Bandar Puncak Alam, Malaysia 